\title{
Activation of somatostatin receptors attenuates pulmonary fibrosis
}

\author{
R Borie, ${ }^{1,{ }^{*}}$ A Fabre, ${ }^{1,2,{ }^{*}}$ F Prost, ${ }^{1}$ J Marchal-Somme, ${ }^{1}$ R Lebtahi, ${ }^{3}$ S Marchand-Adam, ${ }^{1,4}$ \\ M Aubier, ${ }^{1,4}$ P Soler, ${ }^{1}$ B Crestani ${ }^{1,4}$
}

- Supplementary data are published online only at http:// thorax.bmj.com/content/vol63/ issue 3

${ }^{1}$ INSERM, Unit 700, Paris, France, and Université Paris 7 , Faculté de Médecine Denis Diderot, Paris, France;

${ }^{2}$ Assistance Publique-Hôpitaux de Paris, Hôpital Bichat-Claude Bernard, Service

d'Anatomopathologie, Paris,

France; ${ }^{3}$ Service de Médecine

Nucléaire, Paris, France;

${ }^{4}$ Service de Pneumologie A,

Paris, France

Correspondence to:

Professor B Crestani, Service de

Pneumologie A, Hôpital Bichat-

Claude Bernard, 46 rue Henri

Huchard, 75018 Paris, France

bruno.crestani@bch.aphp.fr

${ }^{*} \mathrm{R}$ Borie and A Fabre contributed equally to this work.

Received 20 January 2007 Accepted 27 July 2007

Published Online First

19 October 2007

\begin{abstract}
Background and aim: Somatostatin analogues may have antifibrotic properties in the lung. The aim of this study was to evaluate the expression of the five somatostatin receptors sst1 to sst5 in normal and fibrotic mouse lung and the action of SOM230 (pasireotide), a new somatostatin analogue with a long half-life, in bleomycin induced lung fibrosis and in human lung fibroblasts in vitro.
\end{abstract}

Methods: After intratracheal injection of bleomycin, C57BI6 male mice received one daily subcutaneous injection of SOM230 or saline. The lungs were evaluated on days 3, 7 and 14 after administration of bleomycin.

Results: We found that all somatostatin receptors were expressed in the normal mouse lung. The sst2 receptor mRNA expression was increased after bleomycin. SOM230 improved mice survival $169 \%$ vs $44 \%$; $p=0.024)$, reduced lung collagen content at day 14 and decreased lung collagen-1 mRNA at day 7. SOM230 reduced bronchoalveolar lavage inflammatory cell influx at day 3 , decreased lung connective tissue growth factor mRNA and transforming growth factor (TGF) $\beta$ mRNA and increased lung hepatocyte growth factor and keratinocyte growth factor mRNA. The sst2 receptor was strongly expressed in the human lung (normal or fibrotic), particularly by fibroblasts. In vitro, SOM230 reduced BrdU incorporation by control human lung fibroblasts cultured under basal conditions or with TGF $\beta$, and reduced alpha- 1 collagen-1 mRNA expression in TGF $\beta$ stimulated fibroblasts.

Conclusion: We conclude that SOM230 attenuates bleomycin induced pulmonary fibrosis in mice and human lung fibroblasts activation. This study points to a potential new approach for treating pulmonary fibrotic disorders.

Idiopathic pulmonary fibrosis (IPF) is a chronic lung disease which carries a poor prognosis. To date, no treatment has been demonstrated to prevent the evolution of fibrosis in patients with IPF and new therapeutic opportunities are needed. While the pathophysiology of pulmonary fibrosis is poorly elucidated, it is characterised at the microscopic level by fibroblast accumulation and extracellular matrix deposition in the lung, leading to alveolar wall thickening and loss of elasticity. Apart from chronic lung inflammation, which probably participates in the pathophysiology of the disease, ${ }^{1}$ the recruitment, activation and proliferation of fibroblasts are now considered key features during the development of pulmonary fibrosis, and therapeutic agents targeting fibroblasts are being evaluated in IPF. ${ }^{2}$

Somatostatin is an endogenous cyclic peptide initially identified as a regulator of growth hormone secretion. Five somatostatin receptors-sst1, sst2A, sst3, sst4 and sst5 - have been described in humans, that bind somatostatin equally. Although the relative expression and localisation of these receptors vary within organs, their expression in the lung has been poorly studied. In a previous study, our group has shown that human lung fibroblasts, from normal and fibrotic lung, bound radiolabelled somatostatin in vitro. ${ }^{3}$ We also evidenced an increased uptake of radiolabelled octreotide (a somatostatin agonist) in the lung in patients with IPF compared with control patients. ${ }^{3}$ Most importantly, the octreotide uptake correlated with the severity of lung fibrosis. ${ }^{3}$ Taken together, these data suggested that somatostatin receptors were increased in IPF lungs.

Somatostatin and its pharmacological analogues display antifibrotic activities in vitro and in vivo in different experimental settings. ${ }^{4}$ The pathways involved in this antifibrotic effect are not completely elucidated but inhibition of transforming growth factor $\beta 1$ (TGF $\beta 1$ ) production ${ }^{5}{ }^{6}$ as well as a degree of anti-inflammatory actions ${ }^{7}$ may contribute to the protective effect. However, the antifibrotic effect of somatostatin and its analogues has never been evaluated in the lung.

SOM230 (pasireotide) is a new somatostatin analogue that binds four out of the five sst receptors (sst1, sst2A, sst3 and sst5) and has a long half-life which makes it suitable for therapeutic use. ${ }^{8}$ In this study, we evaluated the antifibrotic effect of SOM230 in a bleomycin induced lung fibrosis model in mice. We quantified the expression and localisation of somatostatin receptors (sst1 to sst5) in the normal and fibrotic lung, and we evaluated whether SOM230 modulated the TGF $\beta$ and connective tissue growth factor (CTGF) profibrogenic pathways Furthermore, we characterised the effect of SOM230 on human lung fibroblasts in vitro.

\section{MATERIAL AND METHODS}

\section{Bleomycin animal model}

Male C57BL/6J mice (R Janvier, Le Genest St Isle, France), aged 6-7 weeks, were kept in accordance with INSERM rules. On day 0 , mice were administered $80 \mu \mathrm{g}$ of bleomycin hydrochloride (Bleomycine Bellon; Aventis, Paris, France) intratracheally, and were randomly assigned to receive either SOM230 $25 \mu \mathrm{g} / \mathrm{kg} /$ day (bleo+SOM mice) or $2.5 \mu \mathrm{g} / \mathrm{kg} / \mathrm{day}$, or an equal volume of saline (bleo+vehicle mice). SOM230 was diluted in $100 \mu \mathrm{l}$ of saline and subcutaneously administered daily, beginning immediately after injection of bleomycin. Mortality was assessed daily over a 14 day period. For further analysis, animals were sacrificed on day 3, 7 or 14 after administration of bleomycin. 
Figure 1 Lung expression of somatostatin receptors. (A-E) Somatostatin (sst) receptor mRNA was quantified by quantitative PCR in the lungs of naive mice (controls (C)) or in mice who received intratracheal bleomycin (Bleo), and were sacrificed on day 3 , day 7 or day 14 after bleomycin, and were treated daily with a subcutaneous injection of SOM230 (25 $\mu \mathrm{g} / \mathrm{kg} /$ day) (SOM) or vehicle (V). mRNA content was expressed as the ratio to the housekeeping gene ribosomal protein L13 (RPL13) ( $n=4-7$ animals for each experimental condition). All somatostatin sst receptor mRNA was present in the lungs of control mice but with very low levels of expression of sst5 (E). After bleomycin instillation, there was increased expression of sst2A (B) and sst5 in bleo+vehicle mice, with a maximum on day 7 , and decreased expression of sst1 (A) and sst4 (D). Expression of sst3 mRNA remained unchanged (C). After bleomycin instillation, SOM230 treatment temporarily increased expression of sst1, partly inhibited the increased expression of sst2A and did not modify expression of sst3, sst4 or sst5. ${ }^{*} p<0.05$. The centre line of the box denotes the median, the extremes of the box the interquartile range and the bars the highest and lowest values.
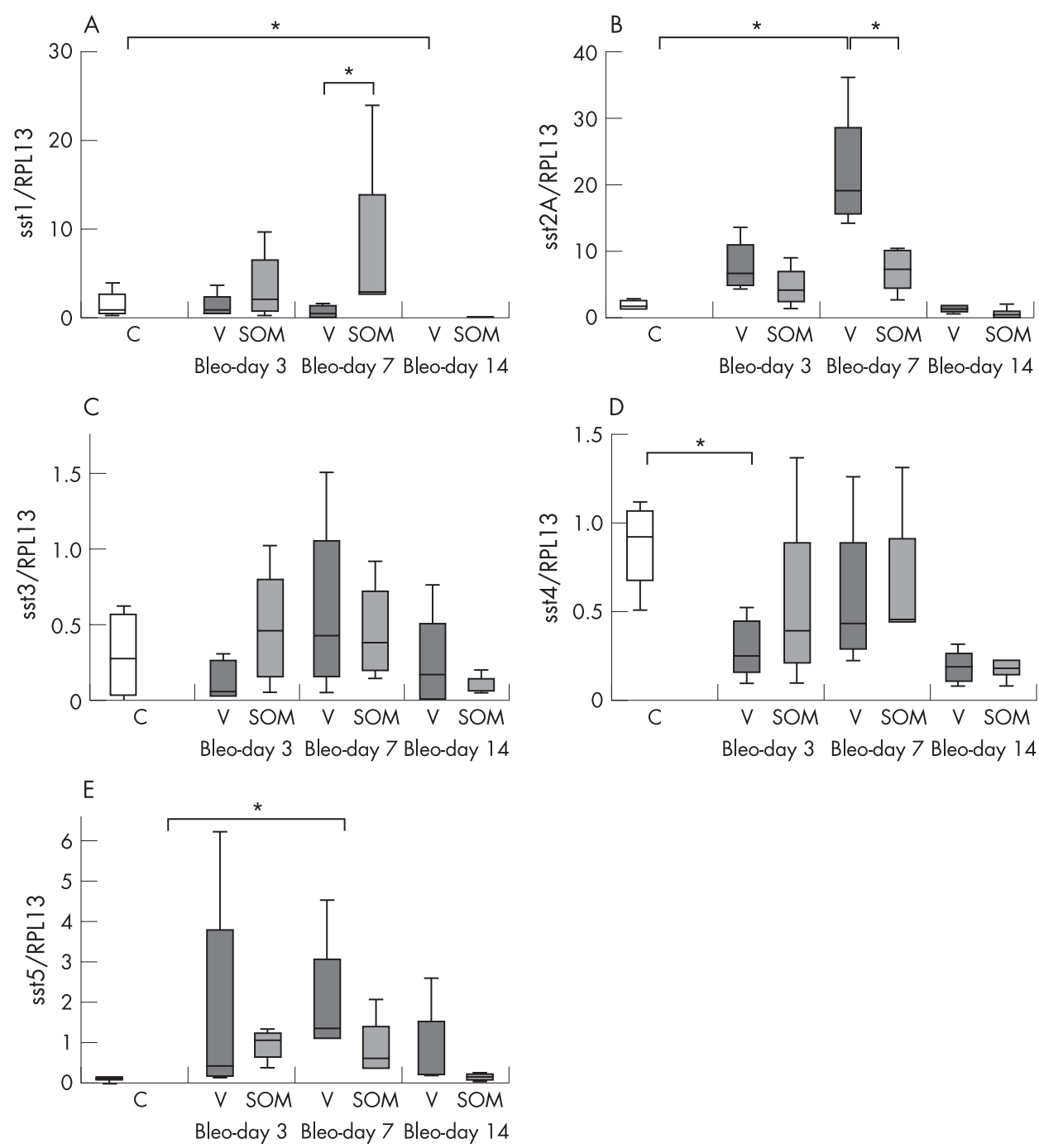

To evaluate the effect of late treatment, SOM230 (25 $\mu \mathrm{g} / \mathrm{kg} /$ day) or vehicle was given from day 5 to day 13. The animals were killed on day 14. Naïve mice were used as controls. The doses of SOM230 used in this study were similar to those used in previous experiments. ${ }^{9}$

In further experiments, controls animals received SOM230 (25 $\mu \mathrm{g} / \mathrm{kg} /$ day) or vehicle for 3, 7 or 14 days, and were sacrificed at each time point ( $n=6$ per time).

\section{Tissue sampling, lung histology, TGF $\beta 1$ assay and mRNA analysis}

At specified time points, the animals were killed and the lungs were freed of blood by perfusion. Bronchoalveolar lavage (BAL) was performed with $1 \mathrm{ml}$ of saline. Total and differential cell counts were estimated. BAL supernatant was stored at $-80^{\circ} \mathrm{C}$ until TGF $\beta 1$ assay.

Total TGF $\beta 1$ was measured after acidification of the samples according to the manufacturer's instructions (Quantikine; R\&D System Europe, Lille, France).

Semiquantitative assessment of lung injury used the grading system described by Inoshima and colleagues. ${ }^{10}$

Lung collagen was quantified in snap frozen right lungs with the Sircol collagen assay (Biocolor Ltd, Newtownabbey, UK).

RNA extraction and real time quantitative PCR were performed on left mouse lungs using standard protocols (see online supplement). Expression of the gene of interest was expressed as a ratio to the ribosomal protein L13 (RPL13) gene, as previously described. ${ }^{11}$

\section{Immunohistochemical detection of somatostatin receptors}

The sst2 receptor was detected by immunohistochemistry on mice samples with a rabbit polyclonal anti-mouse sst2A antibody (ref SS-800; Biotrend, Cologne, Germany) (1/400 dilution). Immunodetection was performed on frozen human lung tissue samples (from three controls and five patients with IPF, diagnosed according to the American Thoracic Society/European Respiratory Society consensus criteria ${ }^{12}$ - the origin of lung samples has been previously described ${ }^{11}$ ), and cultured human fibroblasts, using a polyclonal rabbit antibody to human somatostatin receptor type 2B (ref SS-860; Biotrend) (1/1000 dilution). Standard protocols were used (see online supplement).

\section{Data analysis}

Data are expressed as median (extremes values). Data analysis was performed with the GraphPad Prism 4.0 software (GraphPad software, San Diego, California, USA). Survival between experimental and control groups was studied with a Kaplan-Meier analysis using the log rank test. Experimental groups were compared first with a non-parametric analysis of variance equivalent (the Kruskall-Wallis test) and, if significant, pairwise comparisons were performed with the Mann-Whitney 
Figure 2 Immunohistochemical detection of somatostatin (sst) receptor sst2A in naive mouse lung and after bleomycin instillation. In normal lung $(A)$, sst2A was expressed by alveolar macrophages, epithelial bronchial cells, arterial and bronchial smooth muscle cells, some endothelial cells and some type 2 pneumocytes (inset, arrow). After bleomycin instillation, the number of sst2A positive cells increased on day 3 (B) with a maximum on day 7 (C, D) and then decreased on day $14(\mathrm{E})$. The sst2A positive cells were essentially localised in the inflammatory areas (original magnification: $A, B, C, E: \times 80 ; D: \times 160$; inset: $\times 400$ ).
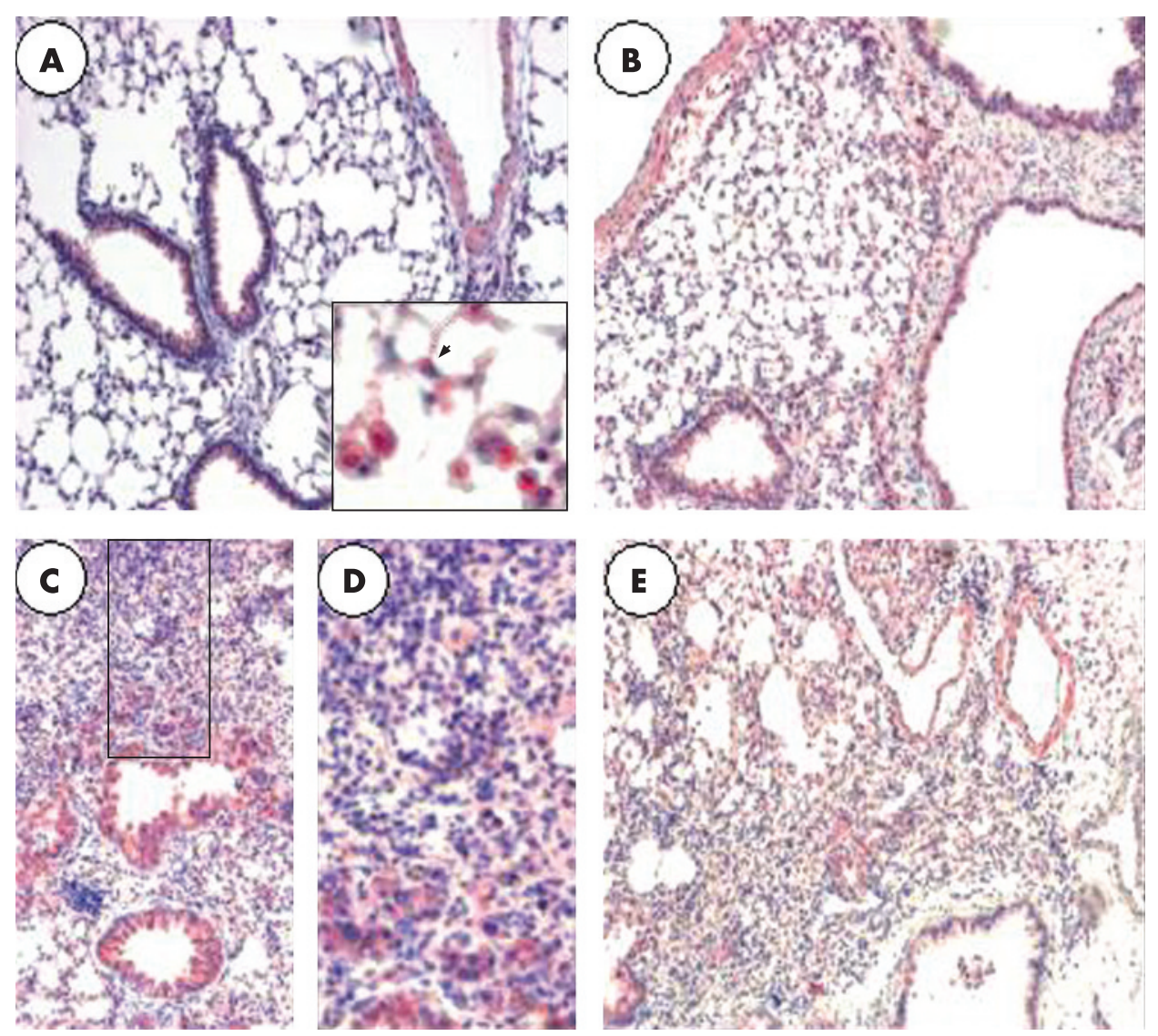

$\mathrm{U}$ test. Comparison of histological scores on day 14 was performed with the Fisher exact test after grouping the scores 0 and 1 and the scores 2 and 3. p Values below 0.05 were considered significant.

\section{RESULTS}

\section{Somatostatin receptors are present in the lung and their expression is modulated after bleomycin instillation}

In naive mice, all (sst1 to sst5) somatostatin receptor mRNA was detected in the lung, with very low levels of expression of

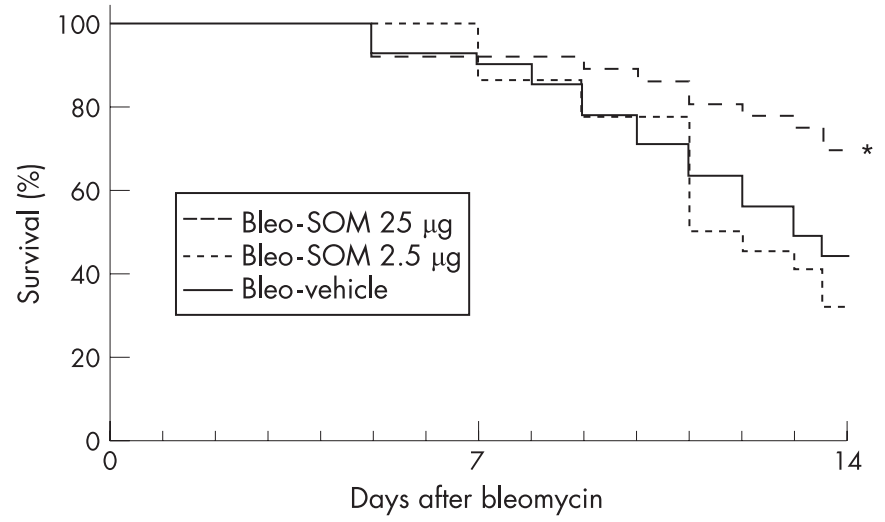

Figure 3 SOM230 (pasireotide) improves mice survival after bleomycin (Bleo) instillation. Treatment with SOM230 (25 $\mu / \mathrm{kg} /$ day) improved survival compared with the bleo+vehicle group ( $69 \%$ vs $44 \%$; $p<0.05$ ). Treatment with SOM230 at a lower dose $(2.5 \mu \mathrm{g} / \mathrm{kg} /$ day $)$ did not improve survival (32\%) ( $n=22-41$ animals for each experimental condition). ${ }^{*} \mathrm{p}<0.05$. sst5 (fig 1). After bleomycin instillation, expression of sst2A and sst5 mRNA was strongly increased (maximum on day 7) whereas expression of sst1 and sst4 mRNA was decreased (fig 1).

Treatment with SOM230 of bleomycin injected mice temporarily increased expression of sst1 (sst1/RPL13 mRNA ratio $=2.9$ (2.5 to 24$)$ on day 7 in bleo+SOM mice vs 0.9 (0.4 to 3.5) for bleo+vehicle mice, $n=4 ; p=0.015)$, and partly inhibited the increase in expression of sst2A (sst2/RPL13 mRNA ratio $=7.4$ (2.8 to 10.6) on day 7 in bleo+SOM mice vs 19 (14.1 to 36.3) for bleo+vehicle mice, $n=4 ; p=0.015$ ) (fig 1).

We characterised the cellular localisation of the sst2A receptor by immunohistochemistry. In the normal murine lung, sst2A was localised to alveolar type 2 pneumocytes, bronchial epithelial cells, alveolar macrophages, arterial smooth muscle cells and some endothelial cells. After bleomycin instillation, the number of sst2A positive cells increased, with a maximum on day 7, essentially because of increased infiltration of sst2A positive cells (macrophages and monocytes) in inflammatory areas (fig 2).

\section{Treatment with SOM230 improved mice survival after bleomycin instillation}

Intratracheal injection of bleomycin induced significant mortality among mice, which typically occurred from day 7. Treatment with SOM230 (25 $\mu \mathrm{g} / \mathrm{kg} /$ day $)$ increased the 14 day survival of mice instilled with bleomycin to $69 \%(n=36)$ compared with $44 \%$ in the bleo+vehicle group ( $n=41, p=0.02)$. Treatment with SOM230 at a lower dose $(2.5 \mu \mathrm{g} / \mathrm{kg} /$ day $)$ did not improve survival (14 day survival $32 \%, \mathrm{n}=22, \mathrm{p}=0.46$ ) (fig 3). 

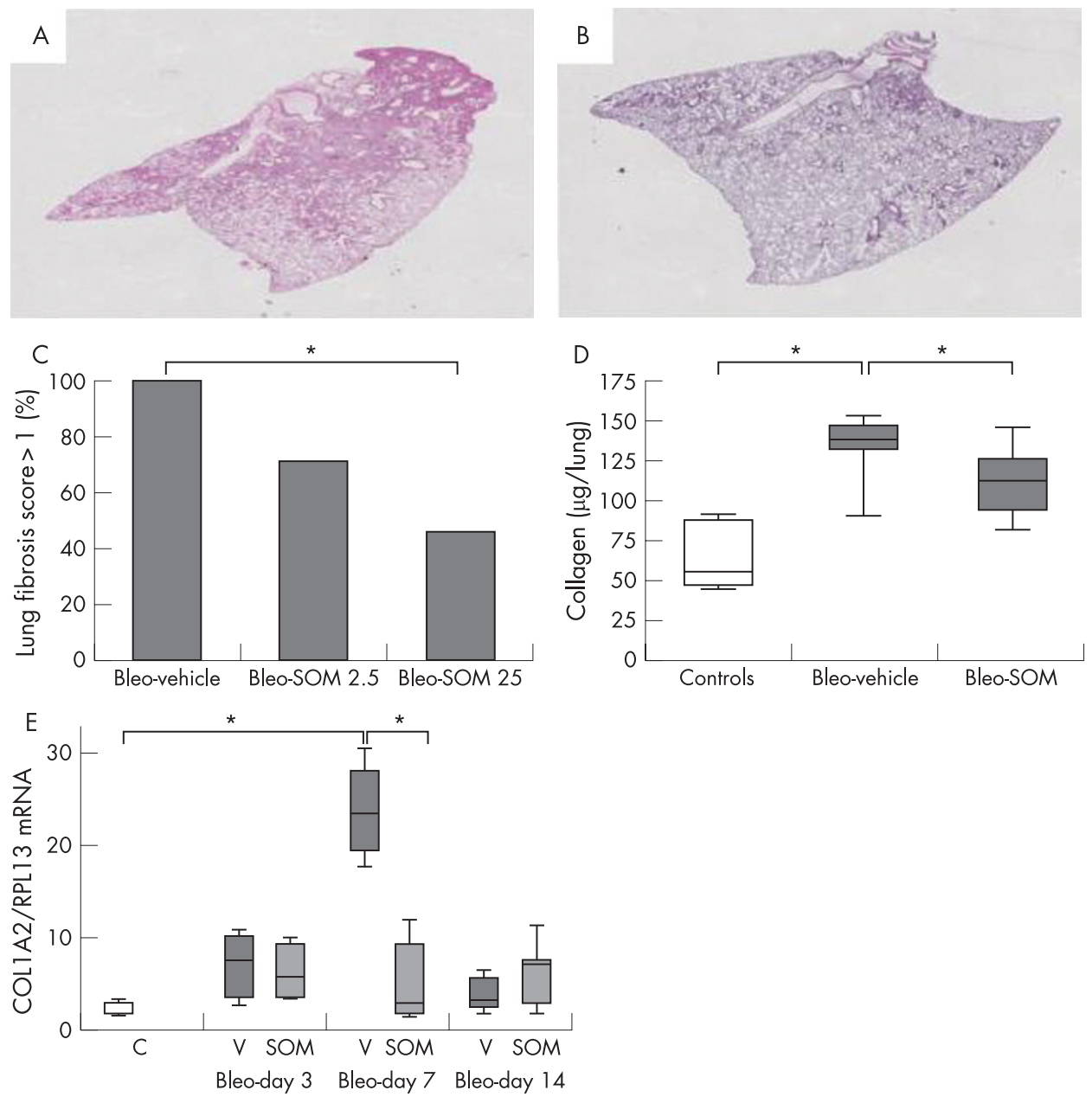

Figure 4 SOM230 (pasireotide) reduces lung fibrosis after bleomycin (Bleo) instillation. Representative lung sections in a bleo+vehicle mice (A) and in a bleo+SOM mouse (25 $\mu \mathrm{g} / \mathrm{kg} /$ day) (B) on day 14 after bleomycin intratracheal injection (haematoxylin-eosin staining, original magnification $\times 10)$. Histological lesions were scored from 0 to 3 (see methods). The percentage of lungs with a lung fibrosis score greater than 1 (lesions involving more than $25 \%$ of the lung) is shown in (C) ( $n=7-11$ animals per group). SOM230 (25 $\mu \mathrm{g} / \mathrm{kg} /$ day) improved the pathological score at day 14 whereas SOM230 at a lower dose $(2.5 \mu \mathrm{g} / \mathrm{kg} /$ day $)$ had a small effect (NS). Lung collagen content was measured by the Sircol assay and expressed as $\mu \mathrm{g}$ collagen/right lung (D). Lung collagen content was increased 14 days after bleomycin instillation in bleo+vehicle mice compared with naive control mice. SOM230 reduced total lung collagen content compared with vehicle ( $n=5-12$ for each experimental condition). (E) Alpha-2 collagen-1 (COL1A2) mRNA expression was assessed by quantitative real time PCR and expressed as the ratio to ribosomal protein L13 (RPL13) mRNA content in the lung of naive mice (controls (C)) and on day 3, day 7 and day 14 after bleomycin instillation. In bleo+vehicle (V) mice, COL1A2 mRNA lung content was increased on day 3, peaked on day 7 and decreased on day 14. SOM230 treatment inhibited the peak of COL1A2 mRNA expression on day 7. SOM230 had no effect at other time points $\left(n=5-7\right.$ animals for each experimental condition). ${ }^{*} p<0.05$. The centre line of the box denotes the median, the extremes of the box the interquartile range and the bars the highest and lowest values.

\section{Treatment with SOM230 attenuated bleomycin induced pulmonary fibrosis}

We analysed the histological changes in the lung of surviving mice at day 14 following bleomycin instillation in bleo+SOM mice $(25 \mu \mathrm{g} / \mathrm{kg} /$ day, $\mathrm{n}=11 ; 2.5 \mu \mathrm{g} / \mathrm{kg} /$ day, $\mathrm{n}=7)$ compared with bleo+vehicle mice. As shown in fig 4, treatment with SOM230 $25 \mu \mathrm{g} / \mathrm{kg} /$ day improved the pathological score at day 14 compared with bleo+vehicle mice $(p=0.03)$ whereas the lower dose $(2.5 \mu \mathrm{g} /$ $\mathrm{kg} /$ day) had no effect. In view of these favourable results, the $25 \mu \mathrm{g} / \mathrm{kg} /$ day dose of SOM230 was used in further experiments.

Table 1 Analysis of bronchoalveolar lavage cellularity in control naive mice and on day 3 after intratracheal bleomycin injection in mice treated with saline or SOM230 (pasireotide)

\begin{tabular}{|c|c|c|c|c|c|}
\hline & $n$ & Cells/ $\mu \mathrm{l}$ & Macrophages/ $\mu \mathrm{l}$ & 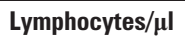 & Neutrophils/ $\mu \mathrm{l}$ \\
\hline Controls & 4 & $230(100-240)$ & 224 (88-237) & $5(0-12)$ & $0(0-0)$ \\
\hline \multicolumn{6}{|l|}{ Day 3} \\
\hline Saline & 6 & 602 (490-1050) & 237 (192-300) & 292 (151-409) & $115(66-280)$ \\
\hline SOM230 & 6 & $365(40-540)$ * & $130(16-300)$ & $68(12-221)^{*}$ & $141(12-161)$ \\
\hline
\end{tabular}

Data are medians (extremes)

${ }^{*} \mathrm{p}<0.05$. 

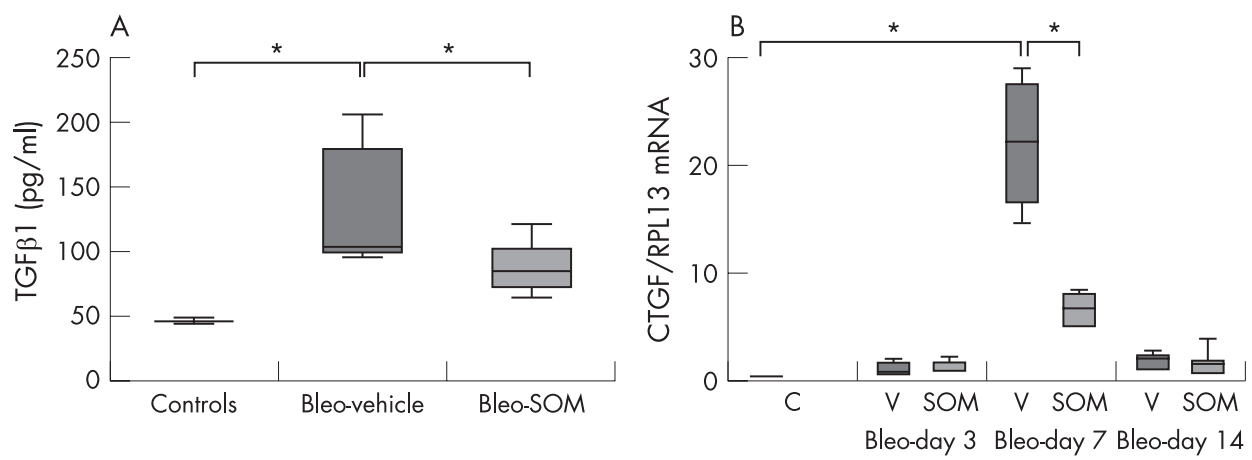

Figure 5 SOM230 (pasireotide) promotes an antifibrotic environment in the lung. (A) On day 14, SOM230 reduced transforming growth factor $\beta 1$ (TGF $\beta 1$ ) concentration in bronchoalveolar lavage fluid compared with bleomycin (bleo)+vehicle animals and control naive mice. (B) Connective tissue growth factor (CTGF) mRNA content was assessed by quantitative real time PCR and expressed as the ratio to ribosomal protein L13 (RPL13) mRNA content in the lung of naive mice (controls) and on day 3, day 7 and day 14 after bleomycin instillation. In bleo+vehicle mice, CTGF mRNA content was increased on day 3 with a maximum on day 7. SOM230 treatment inhibited the peak of CTGF mRNA expression on day 7. SOM230 had no effect on CTGF mRNA content at other time points. The centre line of the box denotes the median, the extremes of the box the interquartile range and the bars the highest and lowest values ( $n=5-9$ animals for each experimental condition). ${ }^{*} p<0.05$.

\section{SOM230 reduced lung collagen concentration}

Treatment with SOM230 reduced lung collagen content on day 14 (112 (21 to 146) $\mu \mathrm{g} /$ lung in bleo+SOM mice versus 139 (90 to 153) $\mu \mathrm{g} /$ lung in the bleo+vehicle mice, $p=0.01$ ) compared with $55 \mu \mathrm{g} /$ lung (45-90) in naive mice ( $p=0.007$ and $p=0.003$ vs bleo+SOM mice and bleo+vehicle, mice respectively) (fig 4).

In bleo+vehicle mice, alpha-2 collagen-1 (COL1A2) mRNA lung content was increased on day 3 after bleomycin instillation, peaked on day 7 and then decreased on day 14 (fig 4). SOM230 treatment strongly inhibited the peak of COL1A2 mRNA expression in the lung on day 7 (COL1A2/RPL13 mRNA ratio $=2.6$ in the bleo+SOM mice vs 23 in the bleo+vehicle mice; $\mathrm{p}=0.01)$. SOM 230 had no effect on COL1A2 mRNA contents at other time points. These results show that the reduction in collagen content on day 14 was preceded by a reduction in COL1A2 mRNA on day 7 .

\section{Treatment with SOM 230 reduced lung inflammation and inhibited the increase in TGF $\beta 1$ and CTGF}

Treatment with SOM230 reduced the alveolar inflammatory cell influx at early times, as assessed by the reduction in total BAL cellularity, BAL macrophages and BAL lymphocyte counts on day 3 (table 1). On day 7 and day 14, BAL cellularity was similar in bleo+SOM and bleo+vehicle mice (data not shown).

TGF $\beta$ and CTGF are two potent profibrogenic factors. Lung TGF $\beta$ mRNA content tended to be lower in bleo+SOM mice on day 7 after bleomycin administration compared with bleo+ vehicle mice (TGF $\beta /$ RPL13 mRNA ratio 2.6 (0.9 to 3.2) in bleo+SOM mice vs $4.8(2.3-16.1)$ in bleo+vehicle mice; $p=0.11)$.
TGF $\beta 1$ concentration in BAL fluid was lower in bleo+SOM mice on day $14(85 \mathrm{pg} / \mathrm{ml}$ (64 to 121)) compared with bleo+vehicle mice (103 pg/ml (96 to 206), $\mathrm{n}=9 ; \mathrm{p}=0.01$ ) (fig 5).

Similarly, SOM230 strongly inhibited the increase in CTGF mRNA induced by bleomycin. After bleomycin instillation, CTGF mRNA content was increased by day 3 , with a maximum by day 7 . Treatment with SOM 230 reduced by $70 \%$ the CTGF/ RPL13 mRNA ratio on day 7 (ratio $=6.4(4.7-8.3), n=5$ ) compared with bleo+vehicle mice (ratio $=22.2$ (14.6-29.2), $\mathrm{n}=4 ; \mathrm{p}=0.01)$ (fig 5).

Furthermore, SOM230 promoted the expression of hepatocyte growth factor (HGF) and keratinocyte growth factor (KGF) (two antifibrotic mediators) after bleomycin, and reduced lung CTGF mRNA content by $30 \%$ when given to naive mice (see online data supplement).

\section{Effect of late treatment with SOM230}

In a further set of experiments, we assessed the protective effect of SOM230 given daily after bleomycin instillation. Mice were started with SOM230 $(25 \mu \mathrm{g} / \mathrm{kg} /$ day $)$ from day 5 after bleomycin instillation until day 13.

In these experiments, the pathological score (score $>1$ : 5/9 bleo+vehicle animals vs $3 / 8$ bleo+SOM animals) and lung collagen content (79.4 (61 to 128) $\mu \mathrm{g} / \mathrm{lung}$ in bleo+SOM mice vs 93.4 (56 to 130) $\mu \mathrm{g} /$ lung in bleo+vehicle mice) tended to be lower in bleo+SOM mice (NS). TGF $\beta$ mRNA and TGF $\beta$ BAL concentrations were strongly reduced in bleo+SOM mice on day 14 (fig 6). There was no significant effect on lung CTGF mRNA content on day 14.
Figure 6 Transforming growth factor $\beta 1$ (TGF $\beta 1$ ) concentration in bronchoalveolar lavage (BAL) fluid in late treatment with SOM230 (pasireotide). SOM230 (25 $\mu \mathrm{g} /$ $\mathrm{kg} /$ day) or vehicle was given from day 5 to 13 . On day 14 , SOM230 reduced TGF $\beta 1$ mRNA (A) and TGF $\beta 1$ concentration in BAL fluid $(B)$ compared with vehicle $(n=5-9$ animals for each experimental condition). ${ }^{*} \mathrm{p}<0.05$.
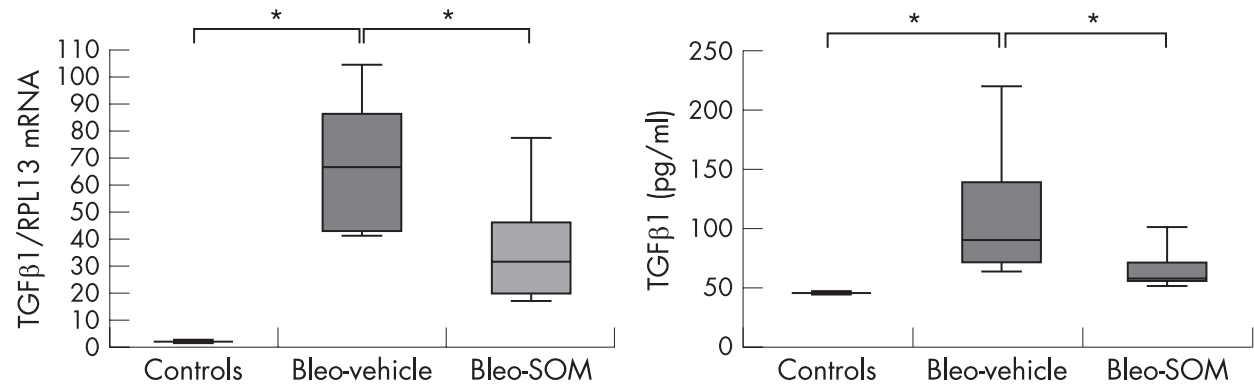
Figure 7 Immunohistochemical detection of the type 2 somatostatin receptor (SST2) in human lung. Expression of SST2 receptor was very low in the normal lung $(A)$ and was essentially detected in alveolar macrophages (AM) and in isolated alveolar cells primarily located in the corners of the alveoli, probably type 2 pneumocytes (arrows). In usual interstitial pneumonia samples (B), we observed strong expression of the receptor in hyperplastic alveolar epithelial cells, endothelial cells (V), fibroblasts, lymphoid aggregates (Ly) and alveolar macrophages (AM). The inset shows a high power view of positive fibroblasts (arrow). Lung fibroblasts cultured from normal lung (C) and from usual interstitial pneumonia (D) expressed the sst2 receptor (original magnification: $A, B$ $\times 250$; inset, $C, D \times 400$ ).
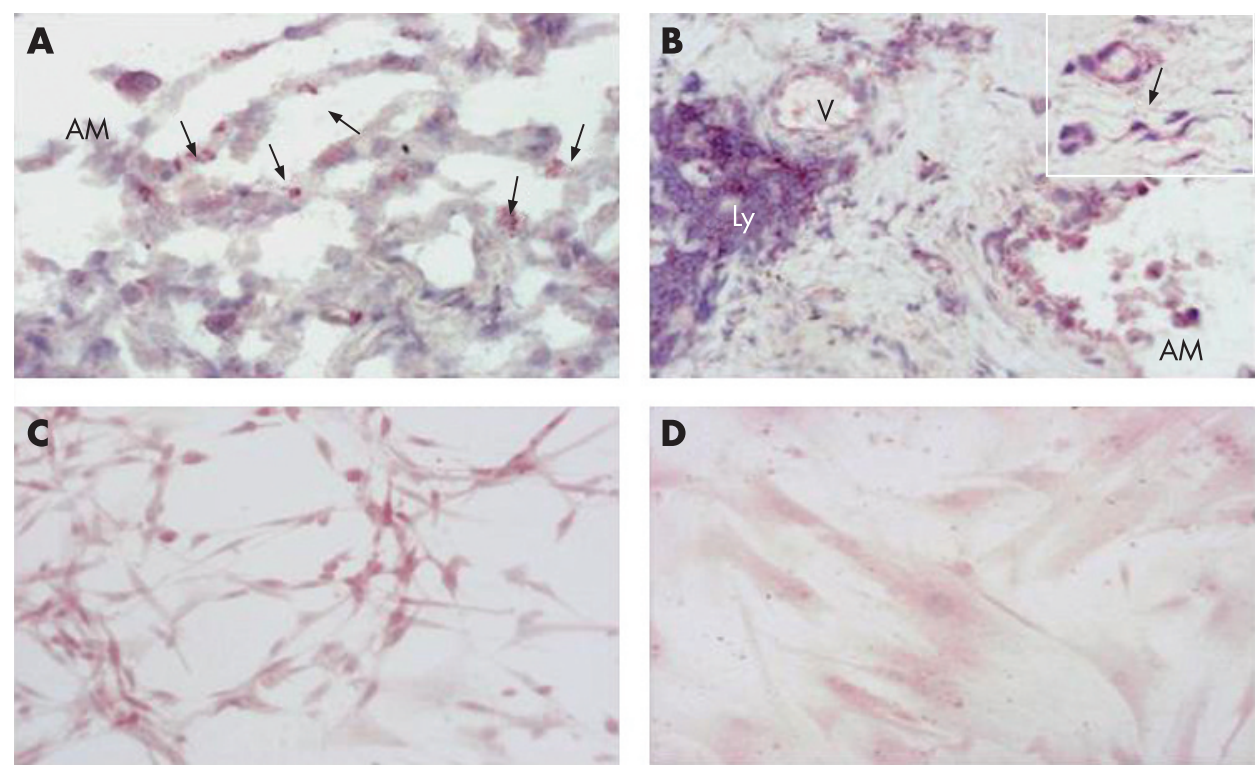

\section{Immunohistochemical detection of the sst2 receptor in human lung (fig 7)}

Expression of the sst2 receptor was very low in the normal lung, and was essentially detected in alveolar macrophages and in isolated alveolar cells primarily located in the corners of the alveoli, representing most probably type 2 pneumocytes. The receptor was not detected in endothelial cells. In the fibrotic lung, we observed strong expression of this receptor in hyperplastic alveolar epithelial cells, endothelial cells and fibroblasts as well as a predominance of the expression of the sst2 receptor in areas of dense fibrosis.

In vitro, fibroblasts cultured from normal lung and fibrotic lung strongly expressed the sst2 receptor, as assessed by immunohistochemistry (fig 7). The intensity of labelling was similar in the two groups.

\section{DISCUSSION}

To our knowledge, this is the first study describing the antifibrotic action of a somatostatin analogue in pulmonary fibrosis. Our results demonstrate (1) that somatostatin receptors are expressed in the lung and are increased during bleomycin induced lung fibrosis in mice and in IPF in humans and (2) that SOM230, a new pharmacological analogue of somatostatin, has a protective effect in bleomycin induced pulmonary fibrosis in mice, as daily treatment with SOM230 improved survival, reduced the lung pathological score and lung inflammation, reduced lung collagen content and lung collagen mRNA expression, inhibited expression of profibrotic mediators (TGF $\beta$ and CTGF) and increased expression of two antifibrotic mediators (HGF and KGF). Although less marked, the antifibrotic effect of SOM230 was also apparent when treatment with SOM230 began 5 days after bleomycin instillation. This suggests that SOM230 may have a therapeutic effect on an ongoing fibrotic process. Furthermore, in in vitro studies (see online supplement), incubation with SOM230 inhibited the proliferation and collagen-1 mRNA expression of human lung fibroblasts.

Emerging data suggest that somatostatin may have interesting antifibrotic properties, both in vitro and in vivo, which we have confirmed in this study using an in vivo model of lung fibrosis.
Firstly, we demonstrated expression of somatostatin receptors in the lung. All sst receptor mRNA was detected in mice lung, although the sst5 receptor was expressed at a very low level. Interestingly, sst receptor mRNA expression appeared to be differentially modulated following bleomycin induced lung fibrosis: expression of sst2A and sst5 mRNA was strongly increased, expression of sst 1 and sst 4 mRNA was decreased whereas expression of sst3 mRNA remained unchanged. The increased expression of the sst2 receptor is of paramount importance as the sst2 receptor is thought to play a prominent role in the biological effects of somatostatin analogues. ${ }^{13}$ Increased mRNA expression was associated with an increase in sst2 positive cells on immunohistochemistry. The latter results are reminiscent of our previous report of increased uptake of radiolabelled octreotide in patients with IPF. ${ }^{3}$

Interestingly, both inflammatory cells and resident lung cells expressed the sst2 receptor in mice and human samples, as detected by immunohistochemistry. In the bleomycin mouse model, increased expression of sst2 was due, at least in part, to an influx of inflammatory cells, particularly monocytes and macrophages. Expression of sst2 has been shown to be upregulated in activated monocytes. ${ }^{14}$ Our results support data indicating that somatostatin analogues exert anti-inflammatory effects on lymphocytes, macrophages and neutrophils. ${ }^{15-20}$ Interestingly, SOM230 reduced alveolar inflammatory cell influx on day 3 , demonstrating an anti-inflammatory action of the compound in this model.

Although somatostatin and its analogues have shown interesting antifibrotic properties in a number of animal models, they have never been tested previously in a model of pulmonary fibrosis. Octreotide is the most extensively studied molecule in this field. In rats, octreotide inhibits the development of liver fibrosis induced by extrahepatic biliary obstruction or carbon tetrachloride poisoning, ${ }^{21} 22$ inhibits oesophageal or digestive fibrosis induced by radiation ${ }^{63}$ and decreases the accumulation of connective tissue in a murine model of hepatic schistosomiasis. ${ }^{24}$ Somatostatin and its analogues develop their antifibrotic action through different mechanisms. Somatostatin has been shown to promote fibroblast apoptosis in vitro through its sst2 receptor ${ }^{25}$ whereas octreotide inhibits the proliferation of skin and orbital fibroblasts. ${ }^{26}{ }^{27}$ In vitro, somatostatin modulates 
fibroblast proliferation through activation of the ERK and MAPkinase pathways. ${ }^{4}$ We show in this study that SOM230 inhibits human lung fibroblast proliferation in vitro. Some data suggest that somatostatin analogues may act through inhibition of TGF $\beta$ production ${ }^{523}{ }^{28}$ although TGF $\beta$ inhibition was not apparent in all models studied. ${ }^{6}$ TGF $\beta$ is the prototypical profibrotic mediator in the lung. TGF $\beta$ has been shown to increase expression of the sst2 receptor in mice, through a Smad4 dependent pathway. ${ }^{29}$ Broad expression of sst receptors in the lung indicates that beside fibroblasts, SOM230 may have many cellular targets, both on resident cells and inflammatory cells, all possibly contributing to its protective action.

Interestingly, SOM230 seemed to downregulate macrophages and lymphocyte lung infiltration on day 3 , but not neutrophils (table 1). This phenomenon could be due to a direct effect of SOM230 on leucocyte survival. Indeed, somatostatin inhibits proliferation and promotes apoptosis in lymphocytes ${ }^{30}$ and reduces macrophage viability, ${ }^{31}$ but such an effect has not been reported with neutrophils. SOM230 could also differentially modulate expression of chemoattractants and adhesion molecules. We did not specifically address this point. In one study, somatostatin did not modify neutrophil migration in vitro in response to different stimuli. ${ }^{32}$

The protective effect of SOM230 in our study is consistently associated with a decrease in TGF $\beta 1$ expression, observed both when SOM230 was given from day 0 to day 14, or when given later, from day 5 to day 14. Reduced expression of TGF $\beta 1$ may contribute to strong inhibition of lung CTGF expression that we observed on day 7 as CTGF expression is selectively induced by TGF $\beta 1 .^{33}$ In vitro, octreotide, a somatostatin analogue, inhibits expression of TGF $\beta$ and CTGF mRNA by hepatic stellate cells. ${ }^{34}$ Whether somatostatin analogues directly modulate CTGF expression is unknown but may be supported by our observation that SOM230 reduced lung CTGF mRNA in control mice treated with SOM230.

Interestingly, our results suggest that SOM230 could exert its antifibrotic properties through increased expression of antifibrotic mediators, such as HGF and KGF (see online supplement). HGF and KGF are produced mainly by fibroblasts..$^{35}$ Our group has previously shown that human lung fibroblasts cultured from the IPF lung have a reduced capacity to secrete $\mathrm{HGF}$ and $\mathrm{KGF}^{36}{ }^{37}$ and to activate proHGF. ${ }^{11}$ Reduced expression of TGF $\beta 1$ by SOM230 explains the increase in HGF and KGF expression as TGF $\beta 1$ is a known inhibitor of HGF and KGF expression. ${ }^{35}$

We observed that endothelial cells expressed the sst2 receptor in the lung, both in mice and in human IPF lung. This result is in agreement with previously reported evidence of the effect of SOM230 in reducing endothelial cell proliferation in vitro ${ }^{38}$ and its action as an antiangiogenic drug. ${ }^{39}$ This is particularly interesting as increased vascularity is a hallmark of IPF $^{40}$ and reduction of aberrant angiogenesis reduces the development of bleomycin induced pulmonary fibrosis. ${ }^{41}$ These findings could further explain the antifibrotic effect of SOM230.

We have also shown that SOM230 inhibits collagen-1 mRNA expression by human lung fibroblasts stimulated in vitro with TGF $\beta 1$ (see online data supplement). Interestingly, maximal inhibition was obtained with low concentrations of SOM230 $\left(10^{-10} \mathrm{M}\right)$ that are likely to be obtained in vivo. Somatostatin has been shown previously to directly inhibit expression of collagen and $\alpha$-smooth muscle actin in hepatic stellate cells. ${ }^{42}$ In that study, inhibition of collagen expression was also obtained only with low concentrations of somatostatin $\left(10^{-9} \mathrm{M}\right)$; the authors attributed this effect to desensitisation of somatostatin receptors with higher doses. ${ }^{42}$

In summary, the encouraging results of this study indicate that SOM230 exerts a protective antifibrotic action in vivo in the bleomycin model. SOM230 demonstrates its antifibrotic action, both through an anti-inflammatory effect and a direct effect on lung fibroblasts, as evidenced by our in vitro results obtained on human lung fibroblasts. The encouraging results obtained from this study provide a rationale for clinical trials based on somatostatin analogues in patients with pulmonary fibrosis.

Acknowledgements: SOM230 was a generous gift of Novartis Pharma (Basel, Switzerland). We thank Olivier Thibaudeau and the Plateau de Morphologie IFR 02 for his technical help in the lung histology study.

Funding: AF was supported by a grant from the Collège des Professeurs de Pneumologie and the Association Française pour la Recherche Thérapeutique. SM-A was supported by a grant from the Fondation pour la Recherche Médicale (Prix Mariane Josso). Part of this work was supported by the Legs Poix (Chancellerie des universités de Paris). PS is the recipient of a Contrat d'Interface Inserm-Assistance Publique/Hôpitaux de Paris

Competing interests: None.

Ethics approval: Yes.

\section{REFERENCES}

1. Marchal-Somme J, Uzunhan Y, Marchand-Adam S, et al. Cutting edge: Nonproliferating mature immune cells form a novel type of organized lymphoid structure in idiopathic pulmonary fibrosis. J Immunol 2006;176:5735-9.

2. Selman M, Thannickal VJ, Pardo A, et al. Idiopathic pulmonary fibrosis. Pathogenesis and therapeutic approaches. Drugs 2004;64:405-30.

3. Lebtahi R, Moreau S, Marchand-Adam S, et al. Increased uptake of 111 ln-octreotide in idiopathic pulmonary fibrosis. J Nucl Med 2006;47:1281-7.

4. Lahlou H, Saint-Laurent N, Estève JP, et al. SST2 somatostatin receptor inhibits cell proliferation through Ras-, rap1-, and B-Raf-dependent ERK2 activation. J Biol Chem 2003;278:39356-71.

5. Gunal Al, Duman S, Sen S, et al. By reducing TGF beta 1, octreotide lessens the peritoneal derangements induced by a high glucose solution. J Nephrol 2001:14:184-9.

6. Wang J, Zheng $\mathrm{H}$, Hauer-Jensen M. Influence of short-term octreotide administration on chronic tissue injury, transforming growth factor beta (TGF-beta) overexpression, and collagen accumulation in irradiated rat intestine. J Pharmacol Exp Ther 2001;297:35-42.

7. Valatas V, Kolios G, Manousou P, et al. Octreotide regulates CC but not CXC LPS induced chemokine secretion in rat Kupffer cells. Br J Pharmacol 2004:141:477-87.

8. Bruns C, Lewis I, Briner U, et al. SOM230: a novel somatostatin peptidomimetic with broad somatotropin release inhibiting factor (SRIF) receptor binding and a unique antisecretory profile. Eur J Endocrinol 2002;146:707-16.

9. Silva AP, Bethmann K, Raulf $F$, et al. Regulation of ghrelin secretion by somatostatin analogs in rats. Eur J Endocrinol 2005;152:887-94.

10. Inoshima I, Kuwano K, Hamada N, et al. Anti-monocyte chemoattractant protein-1 gene therapy attenuates pulmonary fibrosis in mice. Am J Physiol Lung Cell Mol Physiol 2004;286:L1038-44.

11. Marchand-Adam S, Fabre A, Mailleux AA, et al. Defect of pro-hepatocyte growth factor activation by fibroblasts in idiopathic pulmonary fibrosis. Am J Respir Crit Care Med 2006;174:58-66.

12. American Thoracic Society/European Respiratory Society international multidisciplinary consensus classification of the idiopathic interstitial pneumonias. Am J Respir Crit Care Med 2002;165:277-304.

13. Olias G, Viollet $\mathrm{C}$, Kusserow $\mathrm{H}$, et al. Regulation and function of somatostatin receptors. J Neurochem 2004;89:1057-91.

14. Oomen SP, Hofland LJ, van Hagen PM, et al. Somatostatin receptors in the haematopoietic system. Eur J Endocrinol 2000;143(Suppl 1):S9-14.

15. Blum AM, Metwali A, Mathew RC, et al. Granuloma T lymphocytes in murine schistosomiasis mansoni have somatostatin receptors and respond to somatostatin with decreased IFN- $\gamma$ secretion. J Immunol 1992;149:3621-6.

16. Elliott DE, Metwali A, Blum AM, et al. T Iymphocytes isolated from the hepatic granulomas of schistosome-infected mice express somatostatin receptor subtype ॥ (SSTR2) messenger RNA. J Immunol 1994;153:1180-1.

17. Talme T, Ivanoff J, Sundqvist KG. Somatostatin is a specific inhibitor of SDF-1alphainduced T cell infiltration. Clin Exp Immunol 2004;135:434-9.

18. Chao TC, Cheng HP, Walter RJ. Somatostatin and macrophage function: modulation of hydrogen peroxide, nitric oxide and tumor necrosis factor release. Regul Pept 1995:58:1-10.

19. Kolasinski SL, Haines KA, Siegel EL, et al. Neuropeptides and inflammation. A somatostatin analog as a selective antagonist of neutrophil activation by substance $P$. Arthritis Rheum 1992;35:369-75. 
20. Adeyemi EO, Savage AP, Bloom SR, et al. Somatostatin inhibits neutrophil elastase release in vitro. Peptides 1990;11:869-71.

21. Tracy TF, Tector AJ, Goerke ME, et al. Somatostatin analogue (octreotide) inhibits bile duct epithelial cell proliferation and fibrosis after extrahepatic biliary obstruction. Am J Pathol 1993;143:1574-8.

22. Fort J, Oberti F, Pilette $\mathrm{C}$, et al. Antifibrotic and hemodynamic effects of the early and chronic administration of octreotide in two models of liver fibrosis in rats. Hepatology 1998;28:1525-31.

23. Wang J, Zheng $\mathrm{H}$, Sung CC, et al. The synthetic somatostatin analogue, octreotide, ameliorates acute and delayed intestinal radiation injury. Int J Radiat Oncol Biol Phys 1999:45:1289-96.

24. Mansy SS, Yehia HA, Hassan MM, et al. Octreotide decreases connective tissue formation and improves vascular changes associated with hepatic schistosomiasis J Egypt Soc Parasitol 1998;28:23-44.

25. Guillermet-Guibert J, Saint-Laurent N, Davenne L, et al. Novel synergistic mechanism for sst2 somatostatin and TNFalpha receptors to induce apoptosis: crosstalk between NF-kappaB and JNK pathways. Cell Death Differ 2007;14:197208.

26. Priestley GC, Aldridge RD, Sime PJ, et al. Skin fibroblast activity in pretibial myxoedema and the effect of octreotide (Sandostatin) in vitro. $\mathrm{Br} J$ Dermatol 1994:131:52-6.

27. Pasquali D, Vassallo P, Esposito D, et al. Somatostatin gene receptor expression and inhibitory effects of octreotide on primary cultures of orbital fibroblasts from Grave's ophtalmopathy. J Mol Endocrinol 2000;25:63-71.

28. Xidakis C, Ljumovic D, Manousou P, et al. Production of pro- and anti-fibrotic agents by rat Kupffer cells; the effect of octreotide. Dig Dis Sci 2005;50:935-41.

29. Puente E, Saint-Laurent N, Torrisani J, et al. Transcriptional activation of mouse sst2 somatostatin receptor promoter by transforming growth factor-beta. involvement of Smad4. J Biol Chem 2001;276:13461-8.

30. Lattuada D, Casnici C, Crotta K, et al. Inhibitory effect of pasireotide and octreotide on lymphocyte activation. J Neuroimmunol 2007:182:153-9.
31. Armani C, Catalini E, Balbarini A, et al. Expression, pharmacology, and functional role of somatostatin receptor subtypes 1 and 2 in human macrophages. J Leukoc Biol 2007:81:845-55

32. Carolan EJ, Casale TB. Effects of neuropeptides on neutrophil migration through noncellular and endothelial barriers. J Allergy Clin Immunol 1993;92:589-98.

33. Frazier K, Williams S, Kothapalli D, et al. Stimulation of fibroblast cell growth, matrix production, and granulation tissue formation by connective tissue growth factor. J Invest Dermatol 1996;107:404-11.

34. Song SH, Leng XS, Li T, et al. The effect of somatostatin analogue on expression of connective tissue growth factor gene of rat hepatic stellate cells. Zhonghua Wai Ke Za Zhi 2004:42:551-3.

35. Ware LB, Matthay MA. Keratinocyte and hepatocyte growth factors in the lung: roles in lung development, inflammation, and repair. Am J Physiol Lung Cell Mol Physiol 2002;282:L924-40

36. Marchand-Adam S, Marchal J, Cohen M, et al. Defect of hepatocyte growth factor secretion by fibroblasts in idiopathic pulmonary fibrosis. Am J Respir Crit Care Med 2003;168:1156-61.

37. Marchand-Adam S, Plantier L, Bernuau D, et al. Keratinocyte growth factor expression by fibroblasts in pulmonary fibrosis: poor response to interleukin-1beta. Am J Respir Cell Mol Biol 2005:32:470-7.

38. Adams RL, Adams IP, Lindow SW, et al. Inhibition of endothelial proliferation by the somatostatin analogue SOM230. Clin Endocrinol (Oxf) 2004;61:431-6.

39. Jia WD, Xu GL, Xu RN, et al. Octreotide acts as an antitumor angiogenesis compound and suppresses tumor growth in nude mice bearing human hepatocellular carcinoma xenografts. J Cancer Res Clin Oncol 2003;129:327-34.

40. Renzoni EA, Walsh DA, Salmon M, et al. Interstitial vascularity in fibrosing alveolitis. Am J Respir Crit Care Med 2003;167:438-43.

41. Hamada N, Kuwano K, Yamada M, et al. Anti-vascular endothelial growth factor gene therapy attenuates lung injury and fibrosis in mice. J Immunol 2005;175:1224-31.

42. Reynaert H, Rombouts K, Jia Y, et al. Somatostatin at nanomolar concentration reduces collagen I and III synthesis by, but not proliferation of activated rat hepatic stellate cells. Br J Pharmacol 2005:146:77-88.

\section{Lung alert}

\section{A role for squamous metaplasia in COPD airway obstruction}

Airway wall thickening has been established as an important factor in airway obstruction in patients with COPD, and squamous metaplasia of columnar epithelium correlates with the severity of airway obstruction. Here, through a number of experiments, the authors provide evidence for a mechanistic link between these two processes.

An in vitro model of airway squamous metaplasia was created using human airway bronchial cells in serial culture which closely resembled metaplastic squamous epithelium in COPD in vivo. The levels of interleukin (IL)-1 $\beta$ and IL-1 $\alpha$ were increased as cells underwent squamous metaplasia, with IL-1 $\beta$ and IL- $1 \alpha$ genes among the most highly induced during epithelial cell passage. Levels of transforming growth factor $\beta$ (TGF- $\beta$ ), a fibrinogenic cytokine activated via the integrins $\alpha v \beta 6$ and $\alpha v \beta 8$, was also increased with increasing disease severity.

The authors co-cultured squamous metaplastic cells and human airway fibroblasts and analysed the changes in COPD lungs in pneumonectomy samples. They then put forward a model whereby squamous metaplastic epithelial cells activated fibroblasts through IL-1 $\beta$ dependent upregulation of integrin $\alpha v \beta 8$ on small airway fibroblasts. This resulted in TGF- $\beta$ activation, increased matrix production and contractility and, ultimately, airway wall thickening.

This study did not evaluate the effect of the basement membrane on paracrine interactions between epithelial cells and fibroblasts, but highlights a potentially important role for squamous metaplastic cells in the pathogenesis of airway obstruction in COPD.

- Araya J, Cambier S, Markovics JA, et al. Squamous metaplasia amplifies pathologic epithelial-mesenchymal interactions in COPD patients. J Clin Invest 2007:117:3551-62.

\section{Magnus Dillon}

Correspondence to: M Dillon, SHO Respiratory Medicine, Royal Free Hospital, London, UK; magnus.dillon@royalfree.nhs.uk 